DOI: http://doi.org/10.21698/simi.2018.fp21

\title{
USING THE LECHATE TREATMENT TECHNOLOGIES FOR FERTILIZERS
}

\author{
$\underline{\text { Casen Panaitescu}^{1}}$, Cristinel Constandache ${ }^{2}$ \\ ${ }^{1}$ Petroleum-Gas University of Ploiesti, 39 Bucuresti-Ploiesti Blvd., cpanaitescu@upg- \\ ploiesti.ro, Romania \\ ${ }^{2}$ National Institute for Research and Development in Silviculture "Marin Dracea”, 7 Republicii, \\ Focşani, icasvn2006@yahoo.com, Romania
}

\begin{abstract}
Sludge's from leachate treatment are liquid waste. Order 757/2004 regulates the storage of sludge obtained in the process of treatment in the ecological deposit in a proportion of 1:10. Since the sludge usually obtained has a moisture content of over $85 \%$, it is necessary to store it in order to dry it. The new waste legislation in Romania sets an objective for 50\% reduction of waste disposal in landfills by 2020 , which will have an impact on the cost of landfilling sludge in landfills. The paper draws attention to the reuse of the leachate from the ecological deposits in order to fertilize the poor land in Romania.
\end{abstract}

Keywords: fertilizers, leachate, treatment

\section{Introduction}

Legislation on EC waste is hierarchical. The general framework for waste management, including definitions and general principles, is established as the upper level, called "horizontal" legislation. WFD, Council Directive 75/442 / EEC has been revised twice since 1975, firstly in 1991 and then again in 1996. Directive 1999/31 / EC on the landfill of waste has as main objectives the establishment of measures, procedures and guidelines to prevent or reduce adverse effects on the environment and, in particular, pollution of surface water, groundwater, soil, air and the environment in general, including greenhouse effect, and any other subsequent risks for the human health that waste disposal activities may have throughout their life cycle (O’Malley \& Dupre 2005). Current legislation has imposed leachate collection and treatment on all new deposits (Ottawa et al 2007).

The paper proposes the reuse of the leachate from the ecological deposits following it with the help of a mobile wastewater treatment plant (SEM). The resulting product is applied to the soil in order to increase the amount of nutrients.

\section{Materials and methods}

For leachate cleaning, the following procedure is proposed: leachate is sucked through a special device with side slots fixed at the end of the suction hose in the tank number one or second tank of the SEM (depending on its composition - data from the monitoring system of the Mobile Purification Station). The capacity of the two tanks is adjustable from $4 \mathrm{mc}$ to $4 \mathrm{mc}$, making it possible to set them as needed. After the treatment is finished, the sludge will be sucked into the sludge tank.

The measurement of the final parameters of the purified water will be done with the monitoring system of the SEM. It should be noted that from the data recorded up to 


\section{INTERNATIONAL SYMPOSIUM "THE ENVIRONMENT AND THE INDUSTRY", SIMI 2018, PROCEEDINGS BOOK}

now on the quality of the leachate, the presence of heavy metals over the limits of the two landfills was not signaled. The quality of the leachate treated with the mobile wastewater treatment plant is assessed by monitoring the following parameters: $\mathrm{pH}$, conductivity, COD (chemical oxygen demand), $\mathrm{BOD}_{5}$ (biochemical oxygen demand), total nitrogen. For metals $\mathrm{Fe}, \mathrm{Al}, \mathrm{Cu}, \mathrm{Mn}$ no determinations were necessary because both the treated leachate and the soil complied with the plant development requirements. The values were measured using the monitoring system with which the mobile station was equipped. Subsequently, these values were verified in the laboratory by standardized methods of analysis in force (www.anpm.ro).

Another important test that was made (ISO 11269-2:1995). Phytotoxicity was assessed by germination of tomato seeds. 12 seeds were planted at a depth of $0.5 \mathrm{~m}$. The GI - germination index (Tiquia \& Tam 1998), was calculated by counting the number of germinated seeds and analysing the development of the roots for three species of plants in comparison to samples developed on a reference soil:

$$
G I=(G \% * R R G \%) * 100
$$

where: G \% - (number of seeds germinated in a sample / number of seeds germinated in the reference soil) $* 100$; RRG \% - ( the length of the root in a sample / the length of the reference root ) $\times 100$; VI - Germination \%* (root length + shoot length).

In the experiment, the seeds were germinated normally twice in order to determine the energy at the end of the germination period to determine the germination capacity. Normal germs were the most developed. The primary root of the normal germs must be at least equal to the length or diameter of the seed and the germ at least equal to the length of the seed (Tiquia \& Tam 1998, ISO 11269-2:1995, www.usamvcluj.ro).

The next phase after the laboratory tests were finished was the implementation of the obtained results. The soil on which the leachate was applied was a poor soil. The perimeter chosen was based on a pedological mapping process. Thus, there were isolated three perimeters of $1 \mathrm{~km}$ length and $1 \mathrm{~km}$ width on which the scrapping and milling works were carried out for three months during the period the spring, when the land is ready for agricultural crops (Figure 1). The qualities of the soil were analysed before and after the addition of leachate. The application technique was to spread and subsequently incorporate into the soil.

For soil was analysed the humus content (STAS 7184/21- 82) and organic matter content.

The application of the soil quality improvement solution was evaluated periodically by monitoring the physical parameters. The most important physical parameters of the soil (organic matter content, soil type, water retention capacity, nutrient content, soil erosion etc.) subsequently provided the basis for studies for the choice appropriate culture for the treated soil. 


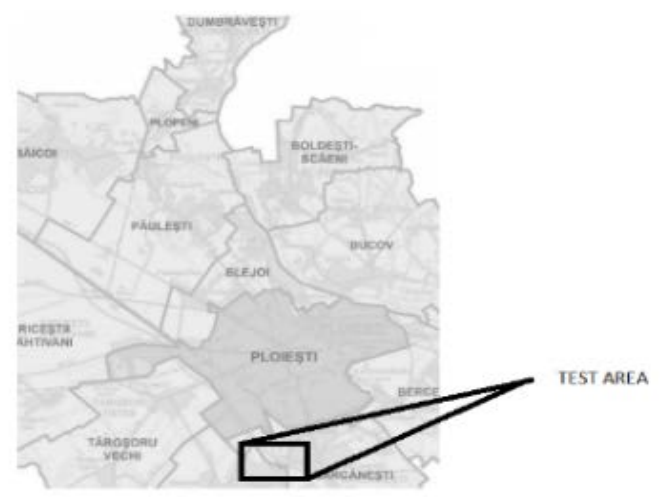

Figure 1. Test area.

\section{Results and discussion}

The medium value for characteristics of the treated leachate are shown in Table 1.

Table 1. The medium values recorded for treated leachate parameters monitored with SEM

\begin{tabular}{lccccc}
\hline Parameter & $\begin{array}{c}\mathrm{pH} \\
\mathrm{units} \mathrm{pH}\end{array}$ & $\begin{array}{c}\mathrm{COD} \\
\mathrm{mg} / \mathrm{l}\end{array}$ & $\begin{array}{c}\mathrm{BOD}_{5} \\
\mathrm{mg} / \mathrm{l}\end{array}$ & Organic matter, $\%$ & $\begin{array}{c}\text { Total nitrogen } \\
\mathrm{mg} / \mathrm{l}\end{array}$ \\
\hline 1. & 7.1 & 118 & 21 & 31 & 11.8 \\
\hline 2. & 7.2 & 111 & 18 & 22 & 14.5 \\
\hline 3. & 7.6 & 115 & 20 & 28 & 18.1 \\
\hline 4. & 7.4 & 127 & 21 & 26 & 22.2 \\
\hline 5. & 7.8 & 108 & 23 & 30 & 16.1 \\
\hline 6. & 7.8 & 92 & 18 & 28 & 16.8 \\
\hline 7. & 7.6 & 120 & 19 & 29 & 28.4 \\
\hline 8. & 7.9 & 113 & 21 & 26 & 26.5 \\
\hline 9. & 7.6 & 112 & 21 & 21 & 22.9 \\
\hline 10. & 7.4 & 99 & 22 & 27 & \\
\hline
\end{tabular}

The experimental information was used to train neural networks in order to estimate some soil parameters following the leachate application. The program used was MATLAB ${ }^{\circledR}$ R2012b. The network drive algorithm was the Levenberg-Marquardt algorithm (ISO 10390:2005). The data entered into the program resulted in values close to $R=1$, indicating that there is a good correlation between output data and target data. 

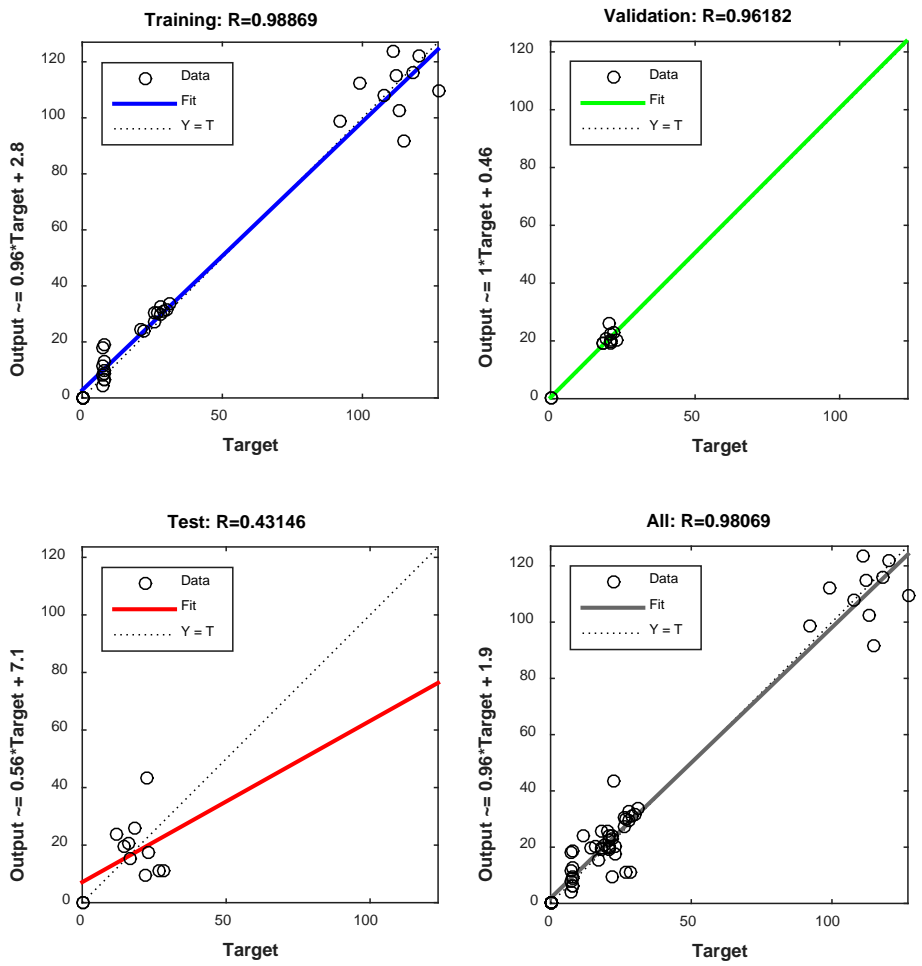

Figure 2. Train of neural networks with Levenberg-Marquardt algorithm.

It can be noticed that the $\mathrm{pH}$ of the treate leachate varied between 8.0-8.3 (pH units) and the measured values for the soil were below 8.0 ( $\mathrm{pH}$ units). The soil was alcalin. Conductivity ranged between $30-40 \mathrm{mS} / \mathrm{cm}$ for the treated leachate. For the soil the conductivity had a minimum value of $20 \mathrm{mS} / \mathrm{cm}$.

The COD value for the treated leachate applied to the soil ranged between $158 \mathrm{mg} / \mathrm{l}$ and $336 \mathrm{mg} / \mathrm{l}$.

The $\mathrm{BOD}_{5}$ value for the treated leachate applied to the soil was of minimum 110 $\mathrm{mg} / \mathrm{l}$ and maximum $324 \mathrm{mg} / \mathrm{l}$. The total nitrogen value for the leachate applied to the soil ranged between $11.8 \mathrm{mg} / \mathrm{l}$ and $28.4 \mathrm{mg} / \mathrm{l}$. For the soil, the maximum recorded value of total nitrogen was of $10.9 \mathrm{mg} / \mathrm{l}$.

The results have shown that there are no significant changes in $\mathrm{pH}$ for the analysed soil. The nitrification process took place, the ammonia being converted first into nitrites and then nitrates. The degradation of organic matter in the soil has ensured the need for ammonia. 


\section{INTERNATIONAL SYMPOSIUM "THE ENVIRONMENT AND THE INDUSTRY", SIMI 2018, PROCEEDINGS BOOK}

The low amount of nitrogen in the soil is correlated with a small amount of organic matter. The increase of the organic matter content to $0.2 \%$ shows that there are conditions fulfilled for assessing the land quality and establishing its use.

The mean value obtained for GI was $81.24 \%$, higher than $80 \%$, indicating an optimal development environment for tomatoes.

\section{Conclusions}

The results of the research are reflected in the development of a leachate treatment technology based on modern concepts, namely: high purification rates and reduced amounts of generated mud. A successful criterion is the reduction of the amount of waste generated, the share and level of training of the personnel employed in the research activities, the high technical and technological level (Buzoianu et al 2016).

In the process of identification of the strengths the following were taken into account: the advantages of a proposal that improves the management of sludge and waste; the advantages of partners that store waste against competition in the field the ecological landfills of partner waste in the project are renowned in the field; the resources and the equipment that were used in the project show a vast experience in the field of waste water treatment / leachate treatment research, nanotechnologies, the use of modern technologies in soil fertilization in forestry and the treatment and disposal of waste. The financial resources used, the location that was chosen previously, the experience in the implementation of European projects and not only, alongside all the partners involved, have led to the improvement of the leachate management at national level.

The strengths capture positive internal aspects and add value to competitors, monitoring major economic agents with a high risk of pollution (Panaitescu \& Bucuroiu 2014). Due to the monitoring of the leachate treatment process, the degree of pollution that exists in household waste deposits will always be known. The opportunities evaluate the external attractive factors that represent elements of which the project team can take advantage.

Treated leachate leads to improved enzyme activity in the soil as well as microbial activity due to superior organic matter and nutrients.

\section{References}

Buzoianu, DA, Panaitescu, C, Bombos, M \& Stoica, ME 2016, 'Study on efficiency increasing of biological stage by sequential operating of aeration reactors', Revista de Chimie, vol. 67, no. 5, pp. 962-966.

ISO 11269-2:1995 Soil Quality, 'Determination of the effects of pollutants on soil flora - Effects of chemicals on the emergence and growth of higher plants'.

ISO 11269-2:1995 Soil Quality, 'Establishment of the effects of pollutants on soil flora - Effects of chemicals on the emergence and growth of higher plants'.

ISO 10390: 2005, 'Determination of soil pH in aqueous and saline suspensions and in saturation paste, Romania'.

STAS 7184/21- 82, 'Determination of humus content in soil, Romania'.

O’Malley, MA \& Dupre, J 2005, 'Fundamental issues in systems biology', BioEssays, no. 27, pp. 1270-1276.

Otawa, K, Lee, SH, Yamazoe, A, Onuki, M, Satoh, H \& Mino, T 2007, 'Abundance, diversity and dynamics of viruses on microorganisms in activated sludge processes', Microbial Ecology, no. 53, pp. 143-152. 
Panaitescu, C \& Bucuroiu, R 2014, 'Study on the composition of municipal waste in urban areas of Prahova county', Environmental Engineering and Management Journal, vol. 13, no.7, pp. 1567-1571.

Tiquia, SM \& Tam, NFY 1998, 'Elimination of phytotoxitcity during co-composting of spent pig manure, sawdust litter and sludge', Bioresource Technology, vol. 65, pp. 43-49.

www.anpm.ro

www.usamvcluj.ro/files/teze/gotea.pdf 